Brit. f. vener. Dis. (1972) 48, 137

\title{
'Triple tetracycline' in the treatment of non-gonococcal urethritis in males
}

\author{
R. R. WILLCOX \\ St. Mary's Hospital, London, W.2
}

\section{The problem of non-gonococcal urethritis (NGU)}

This condition continues to present a considerable problem in aetiology and treatment. Once trichomonads have been excluded, further bacteriological search for the cause cannot usually be pursued in the clinic or consulting room, and the recent discovery (e.g. by Dunlop, Hare, Darougar, Jones, and Rice, 1969) that Chlamydia may be cultivated in a significant proportion of cases has not materially altered the problem of immediate diagnosis. In areas of the world in which antibiotics are available without prescription or are extensively used without microscopic examination of the discharge, many cases termed non-gonococcal are probably in fact gonococcal. Nevertheless, in the venereal disease clinics of Great Britain, where smear diagnosis is universal and where cultures are also used in 50 per cent. of male clinics (British Cooperative Clinical Group, 1971), the numbers of cases of NGU in males have in recent years exceeded the numbers of cases of gonorrhoea in men, despite the steep increase in incidence of the latter (Table I) (Fig. 1).

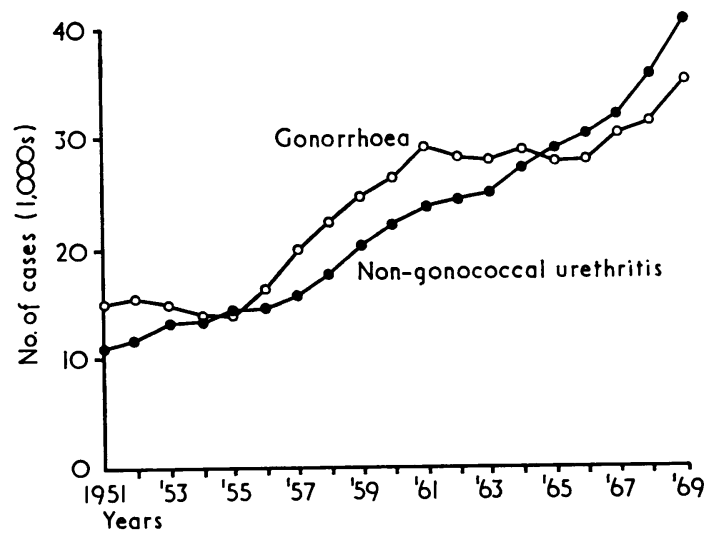

FIG. 1 Urethritis in males in England and Wales, 1951-69

Received for publication May 15, 1971

Presented to the MSSVD at Lyon, France, in May, 1971
TABLE I Urethritis in males in England and Wales (Department of Health and Social Security, 1970)

\begin{tabular}{llll}
\hline Year & \multicolumn{1}{c}{ Gonorrhoea } & & Non-gonococcal urethritis \\
\cline { 1 - 1 } 1951 & 14,975 & & 10,794 \\
1954 & 13,962 & 13,279 \\
1955 & 14,079 & 14,269 \\
1956 & 16,377 & 14,825 \\
1961 & 29,519 & 24,472 \\
1965 & 27,886 & 29,141 \\
1966 & 27,921 & 30,462 \\
1967 & 30,648 & 32.318 \\
1968 & 31,838 & 35,721 \\
1969 & 35,519 & 40,320 \\
\hline
\end{tabular}

For many years the staple treatment of nongonococcal urethritis was a single injection of streptomycin combined with a 5-day course of a sulphonamide, and this remained the preferred therapy on account of its relative cheapness for some years after the more effective but more expensive antibiotics had been discovered.

\section{Comparison of treatment methods}

The results of treating 2,163 cases of previously untreated non-gonococcal urethritis in males are shown in Table II (overleaf).

The tetracyclines, alone or with oleandomycin, proved the most effective, giving cure rates in excess of 80 per cent. in previously untreated cases (Fig. 2, overleaf).

In most instances the treatment with tetracyclines was given for 6 days; if given for less than this time (e.g. with tetracycline phosphate over 4 days) the results were less satisfactory.

The response to tetracycline to which Chlamydia have been shown to be susceptible in vitro and in vivo has lent support to the evidence that these organisms play a causative role in NGU. If this is so it is likely that a 6-day course may not always be sufficient to eradicate the infection. John (1971) has shown that a 10-day course of tetracycline gives better results than a 5-day course, while even better results can be obtained when the treatment is prolonged to 21 days. 
TABLE II Results of treating 2,184 cases of non-gonococcal urethritis by 25 different methods

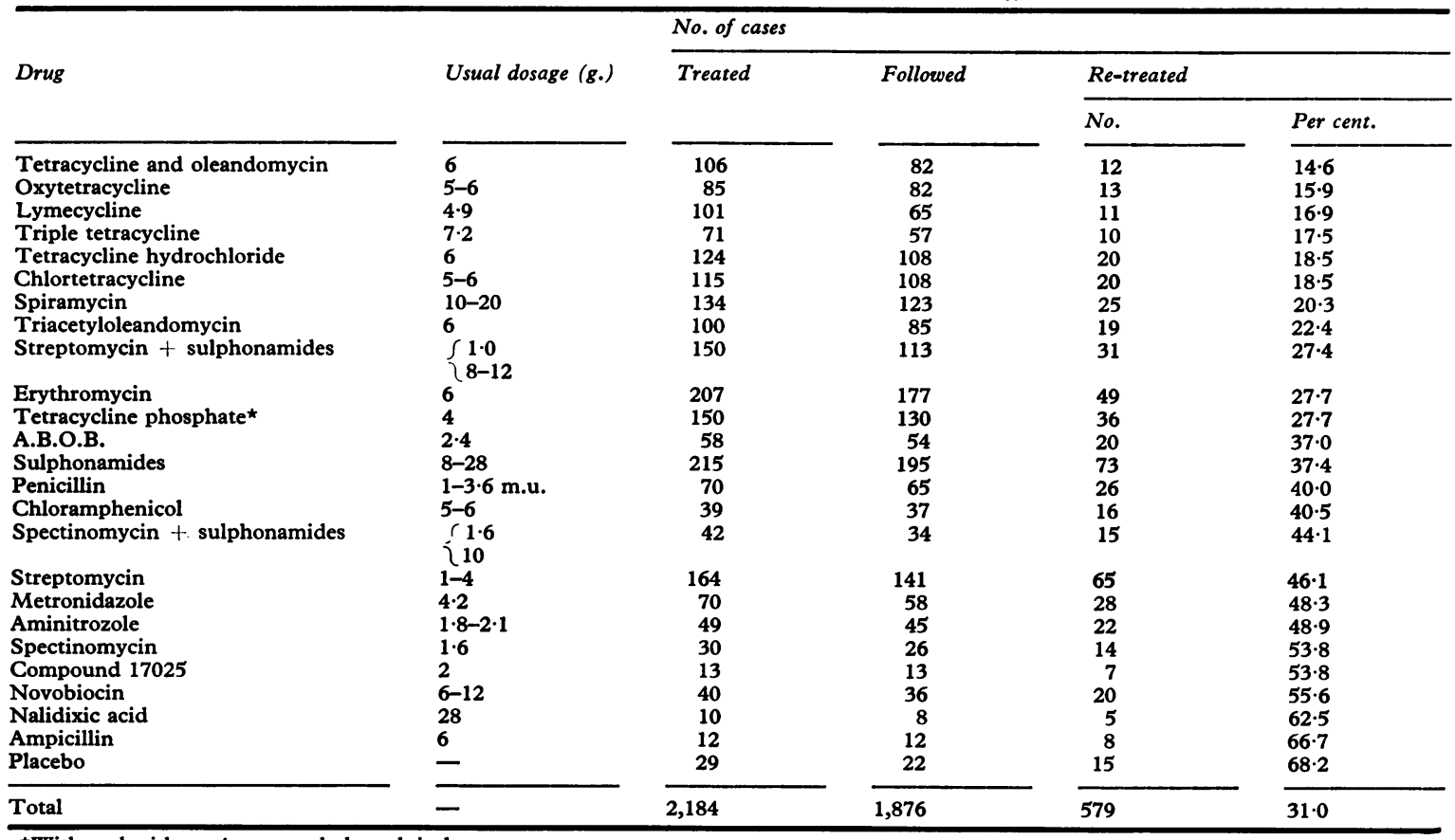

^With and without $4 \mathrm{mg}$. methyl prednisolone

Close behind the tetracyclines in effectiveness, with cure rates in the region of $\mathbf{7 0}$ to 80 per cent., are the macrolid antibiotics, spiramycin, triacetyloleandomycin (alone), and erythromycin; the results obtained

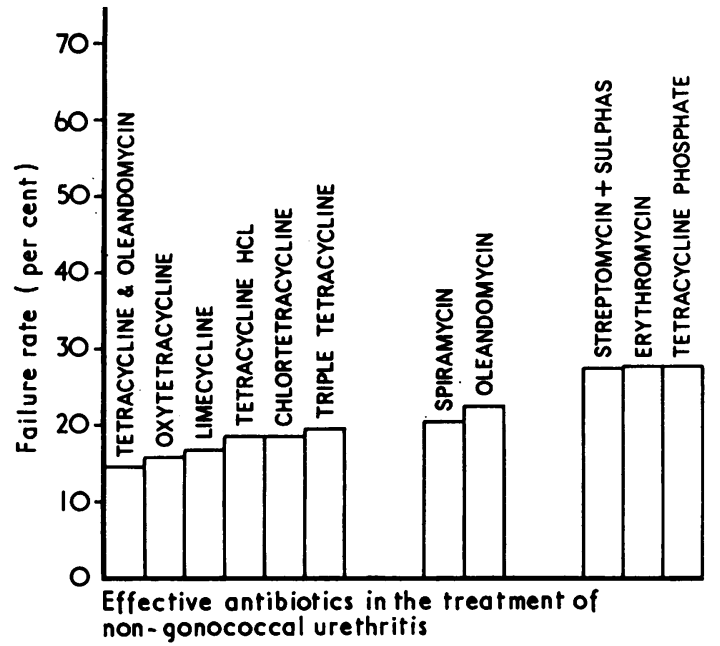

FI G. 2 Effective antibiotics in treatment of non-gonococcal urethritis with erythromycin are about equal to those achieved with streptomycin and sulphonamides combined (Fig. 2).

Drugs of questionable value $(37 \cdot 0-40 \cdot 5$ per cent. failure rate) include the sulphonamides alone, penicillin, and chloramphenicol. Little success or none

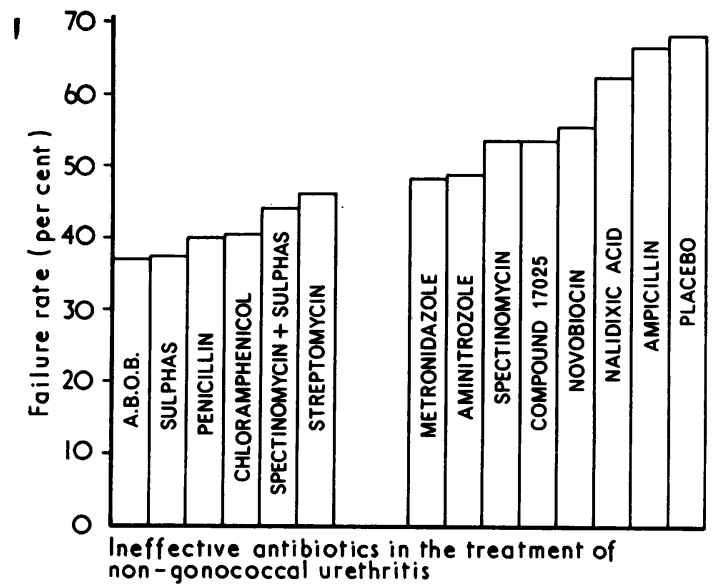

FI G. 3 Ineffective antibiotics in treatment of non-gonococcal urethritis 
was noted with streptomycin, metronidazole, spectinomycin, novobiocin, nalidixic acid, or ampicillin-the last two substances proving the least effective of all (Fig. 3).

\section{Assessment of triple tetracycline}

The most recent tetracycline preparation to be tested is a triple tetracycline mixture ('Deteclo'), each blue 300-mg. tablet of which contains $69 \mathrm{mg}$. demethylchlortetracycline hydrochloride, $115.5 \mathrm{mg}$. chlortetracycline hydrochloride, and $115.5 \mathrm{mg}$. tetracycline hydrochloride. This preparation, which has been considered suitable for twice daily medication, has been shown to be effective against gonorrhoea when given in two oral doses, each of $1.2 \mathrm{~g}$., at an interval of 5 to 6 hours (Willcox, 1969). In NGU a dosage of one tablet twice daily for 4 days was contrasted with $500 \mathrm{mg}$. tetracycline alone given twice daily over the same period by Fowler and Bernstein (1969); no statistically significant difference in the results was reported. However, these authors had 32 to 34 per cent. of failures in those patients who were followed after a 4-day course. It was felt desirable, therefore, to ascertain the effects of a 6-day course and to discover whether it was possible to improve the results by doubling the twice daily dose. Initially 100 male patients with uncomplicated NGU were treated with this drug. Alternate patients were given orally either one $300 \mathrm{mg}$. tablet twice daily for 6 days (total $3.6 \mathrm{~g}$.) or two such tablets twice daily for the same time (total $7 \cdot 2$ g.).

\section{Cases and management}

Gonorrhoea was excluded in all patients by a Gramstained urethral smear before treatment and in some cases by culture also. It was planned that those treated would be observed weekly for 2 weeks and then at approximately
1,2 , and 3 months after treatment. By no means all attended at the times requested, but a sufficient interval was allowed to elapse before assessment to make it possible for all patients to have been followed for 3 months.

In the cases of recurrence, no attempt was made to distinguish relapse from re-infection, except that any recurrence noted after 3 months of freedom from symptoms was automatically assumed to be due to re-infection.

\section{Results}

With $3 \cdot 6$ g. over 6 days (Table III)

Of 50 patients treated, 42 were followed and in 29 the status was satisfactory at the last visit, while 12 patients (28.6 per cent. of those followed) were retreated for a recurrence within three months after treatment. Thus the 6-day course, giving one tablet twice a day, was only marginally better than the 4-day course reported by Fowler and Bernstein (1969).

With $7 \cdot 2$ g. over 6 days (Table III)

Of the 50 patients treated with the higher dosage, 41 were followed and the status was satisfactory at the last visit in 31 of them. One patient subsequently developed a fresh gonococcal infection and eight (19.5 per cent. of those followed) were re-treated for a recurrence of NGU within three months after treatment. The results obtained with two tablets of triple tetracycline given twice daily for six days, giving a cure rate of 80.5 per cent., were thus comparable with those achieved with other tetracyclines given as one tablet or capsule four times a day over the same period.

Subsequently the trial was extended, and in all 143 cases were finally included. Of the 72 treated with $3.6 \mathrm{~g}$. over 6 days, 59 were followed and eighteen

TABLE III Results obtained with triple tetracycline

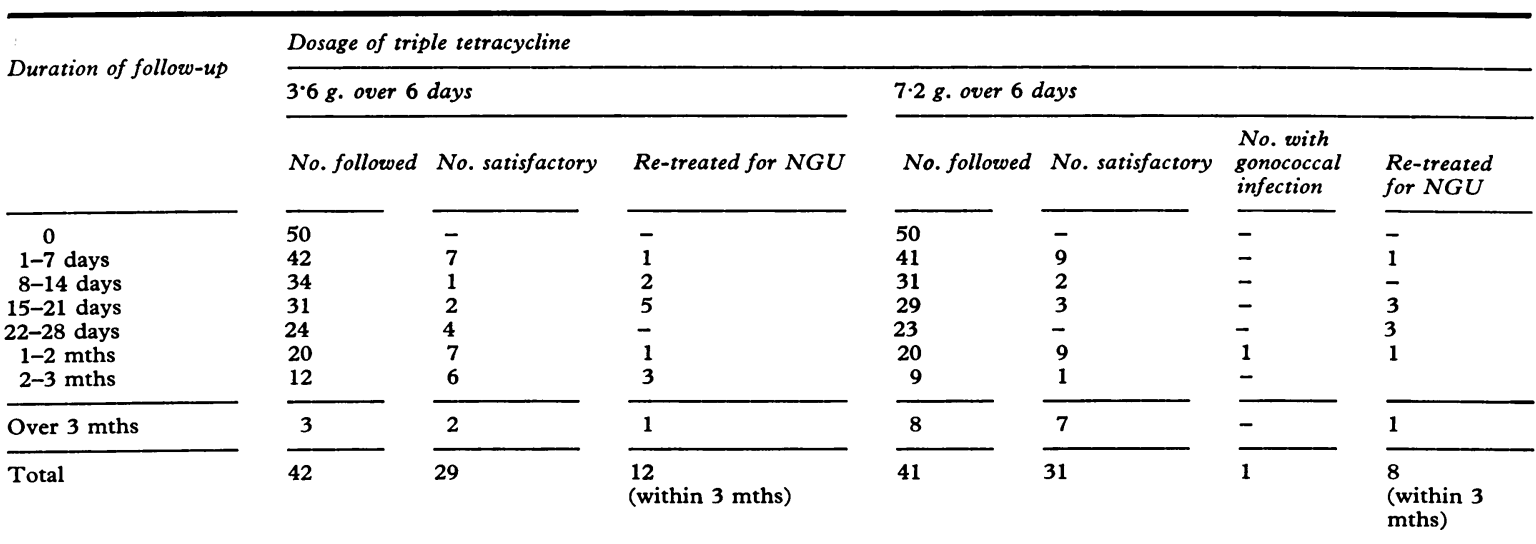


(30.5 per cent.) required re-treatment. 71 patients each received $7 \cdot 2 \mathrm{~g}$. over 6 days; 57 were followed and there were ten cases of failure (17.5 per cent.). The series is not large enough for the difference to be statistically significant. Nevertheless, it was confirmed that the double-dose schedule gave results comparable with that of other tetracyclines, whereas the singledose regime was significantly inferior to the most effective of the other tetracyclines given for the same period.

\section{Summary and conclusions}

(1) In men, the problem of non-gonococcal urethritis (NGU) continues to increase, and in England and Wales there are now more cases diagnosed in the clinics than of gonorrhoea, which itself is also increasing rapidly.

(2) The results obtained in the treatment of 2,184 cases of NGU by 25 different treatment methods are outlined. The best results were achieved with the tetracylines, followed by spiramycin, triacetyloleandomycin, and erythromycin.

(3) In a trial of 'triple tetracycline' when one $300 \mathrm{mg}$. tablet of demethylchlortetracycline, chlortetracycline, and tetracycline was given twice daily for 6 days, the results were no better than those reported by other workers using a 4-day course. On the other hand, when two tablets were given twice a day for 6 days, the results were comparable with those obtained with courses of other tetracyclines given four times a day for 6 days.

The author's thanks are due to Lederle Laboratories, Ltd., for providing the 'Deteclo' used in this study.
References

British Cooperative Clinical Group (1971) Brit. $\mathcal{f}$. vener. Dis., 47, 17

Department of Health and Social Security (1970) Report of Chief Medical Officer for 1969, Appendix C, H.M. Stationery Office, London-see Brit. f. vener. Dis. (1970) 46, 502

Dunlop, E. M. C., Hare, M. J., Darougar, S., Jones, B. R., and RICE, N. S. C. (1969) f. infect. Dis., 120, 463

Fowler, W., and Bernstein, L. S. (1969) Clin. Trials f., 6, 157

John, J. (1971) Brit. F. vener. Dis., 47, 266

WILLCOX, R. R. (1969) Clin. Trials f., 6, 152

'Triple tétracycline' dans le traitement des urétrites non gonococciques chez l'homme SOMMAIRE

(1) Chez l'homme, le problème des urétrites non gonococciques (UNG) continue à revêtir une importance croissante et, en Angleterre et au Pays de Galles, il en est actuellement constaté dans les cliniques plus de cas que de cas de gonococcie, laquelle est elle-même aussi en augmentation rapide.

(2) On donne un aperçu des résultats obtenus dans le traitement de 2,184 cas d'UNG par 25 méthodes thérapeutiques différentes. Les meilleurs résultats furent atteints avec les tétracyclines, suivis de ceux de la spiramycine, de la triacétyloléandomycine et de l'érythromycine.

(3) Au cours d'un essai de la 'triple tétracycline', où un comprimé à $300 \mathrm{mg}$. de déméthylchlortétracycline, chlortétracycline et tétracycline était donné deux fois par jour pendant 6 jours, les résultats n'ont pas été supérieurs aux ceux rapportés par d'autres auteurs avec une série de 4 jours. D'autre part, avec deux comprimés donnés deux fois par jour pendant 6 jours, les résultats ont été comparables à ceux obtenus avec d'autres tétracyclines donnés quatre fois par jour pour un traitement de 6 jours. 